\title{
Rearing gilts breeding with the introduction of "Elevit" feed additive into their diet
}

\author{
G.S. Pokhodnya, Yu.P. Breslavets*, V.M. Breslavets, A.V. Kosov, and N.V. Perevozchikov \\ Belgorod State Agrarian University named after A.Ya. Gorin, Vavilova st. 1, Maysky village, \\ Belgorod district, Belgorod Region, 308503, Russian Federation
}

\begin{abstract}
Our studies have shown that additional introduction of feed additive "Elevit" into the rearing gilts' diet at a dosage of $1.0 ; 1.5 ; 2.0 \%$ during their breeding from 4 to 8 months allows to increase the gilts' live weight by $3.9 ; 7.0 ; 9.5 \%$, respectively, with average daily gains also increasing in comparison to the control group by $6.4 ; 11.6 ; 15.7 \%$. Also, when reaching 8 months, gilts of experimental groups exceeded their peers from the control group in heart mass by $3.2 ; 4.1 ; 6.3 \%$; lungs - by $3.7 ; 4.0$; $4.2 \%$; liver - by $5.1 ; 5.8 ; 6.2 \%$, respectively. When rearing gilts reached the age of 8 months, a study of their reproductive function was carried out. So, we have established that gilts receiving "Elevit" feed additive together with the diet at a dosage of $1.0 ; 1.5 ; 2.0 \%$ exceeded their peers from the control group in fertilization indicator by $4.5 ; 5.4 ; 5.4 \%$, and multifertility by $4.3 ; 6.2 ; 7.5 \%$ respectively. The increase in these indicators led to an increase in the total number of experimental piglets received from rearing sows by 36,$3 ; 47.1 ; 48.7 \%$ compared to control.
\end{abstract}

\section{Introduction}

The most important condition for further pig farming intensification is not conceivable without breeding and timely introduction of rearing gilts with high reproducible function into the main sows' herd of industrial complexes. However, as demonstrated by experience and practice, most pigs do not fully exhibit high productivity in conditions of industrial technology despite their high genetic potential. It was established that in the conditions of industrial technology, animals and especially rearing gilts are affected by various stressors, resulting in disturbancies of sexual function, which is expressed in weak sexual activity, low fertilisation and multifertility $[1,3,4,5,6,7]$.

It is known that the level of animals' productivity depends not only on their genetic potential, but also on the realization of this potential, namely on paratypical factors feeding and keeping [1, 10, 14]. The inferiority and imbalance of diets in rearing gilts' breeding leads to weakening of sexual reflexes, atrophy of the ovaries and a decrease in ovulation $[4,8,10,17]$.

\footnotetext{
${ }^{*}$ Corresponding author: umat_05@mail.ru
} 
At the present stage of intensive animal husbandry, specialists strive to achieve maximum productivity from animals, while trying to reduce production costs, which depend on the quantity and quality of fodder fed.

It is no secret to anyone that a balanced diet in pig farming is a "golden key" to produce large high-quality pork quantities. At the same time, the easiest way to balance the diet for a particular sex-age group of pigs is the use of feed additives. Inclusion of feed additives in addition to the main diet allows to accelerate and improve the digestibility of feed, increase the growth and productive qualities of animals, reduce the production cost $[2,12,13,14$, 17]. Belgorod innovation company "Vita" LLC has created a new feed additive "Elevit". It is made from the germ of wheat caryopsis after a certain treatment. At the same time, this feed additive does not concede to animal-origin feed (chicken eggs, fish meal, skim milk) both in terms of nutritional qualities and chemical composition, and even exceeds them in some parameters $[8,9,10,11,15,16,19,20]$. Based on this, "Elevit" feed additive application in the diets of farm animals acquires important scientific and practical importance.

\section{Materials and methods of research}

The study of the additional introduction influence of domestic feed additive "Elevit" into the rearing gilts' diet on their growth, development and reproductive function was carried out during special research performed on the basis of the advanced pig breeding enterprise of the Belgorod region - APC "Kolkhoz named after Gorin". Methodically, the experiment was organized as follows - 4 groups of 26 rearing gilts were selected. Their age was about the same -4 months. They selected pigs were kept in the same conditions, but their feeding was different. So, gilts of the first control group received the main diet according to the norms of FRCAH, and the gilts of the second, third and fourth experimental groups additionally received "Elevit" feed additive in a dosage of 1.0; 1.5; $2.0 \%$. This feed additive was included in the diets of experimental groups' gilts throughout the growing period from 4 to 8 months. At the end of rearing gilts' growing to 8 months, a control slaughter of 3 heads from each group was carried out to study the development of their internal organs. The rest 23 heads per rearing gilts' group were transferred to the reproduction room, where their reproducible function was studied. Oestrus in gilts was detected twice a day using trailer boars. Artificial insemination of gilts was carried out according to the FRCAH method twice: the first gilts' insemination was carried out immediately after oestrus establishment, and the second - in 24 hours.

\section{Research results}

The influence of "Elevit" feed additive on rearing gilts during their breeding from 4 to 8 months can be judged according to Figure 1 . 


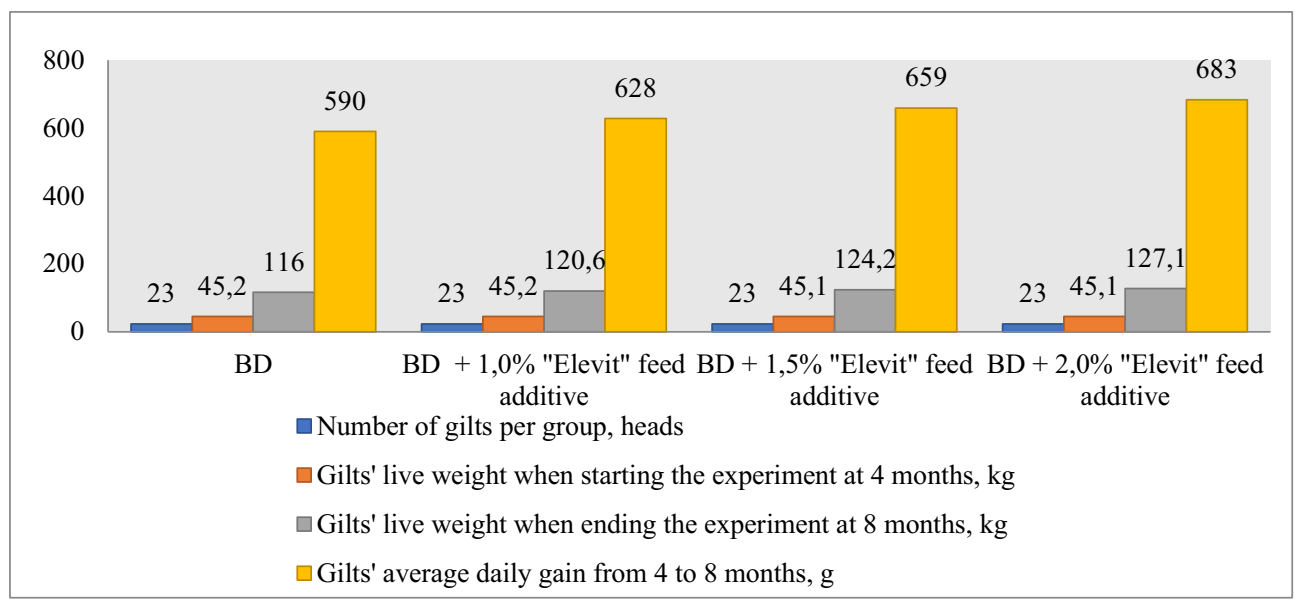

Fig.1. The influence of "Elevit" feed additive on rearing gilts' growth.

Thus, according to Figure 1, additional feeding of "Elevit" feed additive to rearing gilts in addition to the main diet at dosages $1.0 ; 1.5$ and $2.0 \%$ allowed to increase the gilts' live weight by $3.9 ; 7.0 ; 9.5 \%$, respectively, with average daily gains also increasing in comparison with the control group by $6.4 ; 11.6 ; 15.7 \%$.

At the same time, the following should be noted - indicators reflecting the absolute animals' growth do not fully characterize the intensity of the animal organism's growth as the dynamics of absolute live weight growth does not always correctly correlate with the magnitude of the growing weight and the rate of animal's growth. For this reason, after carrying out all the experiments, we have also established an indicator of relative live weight increase in rearing gilts. These indicators are shown further in Fig. 2.

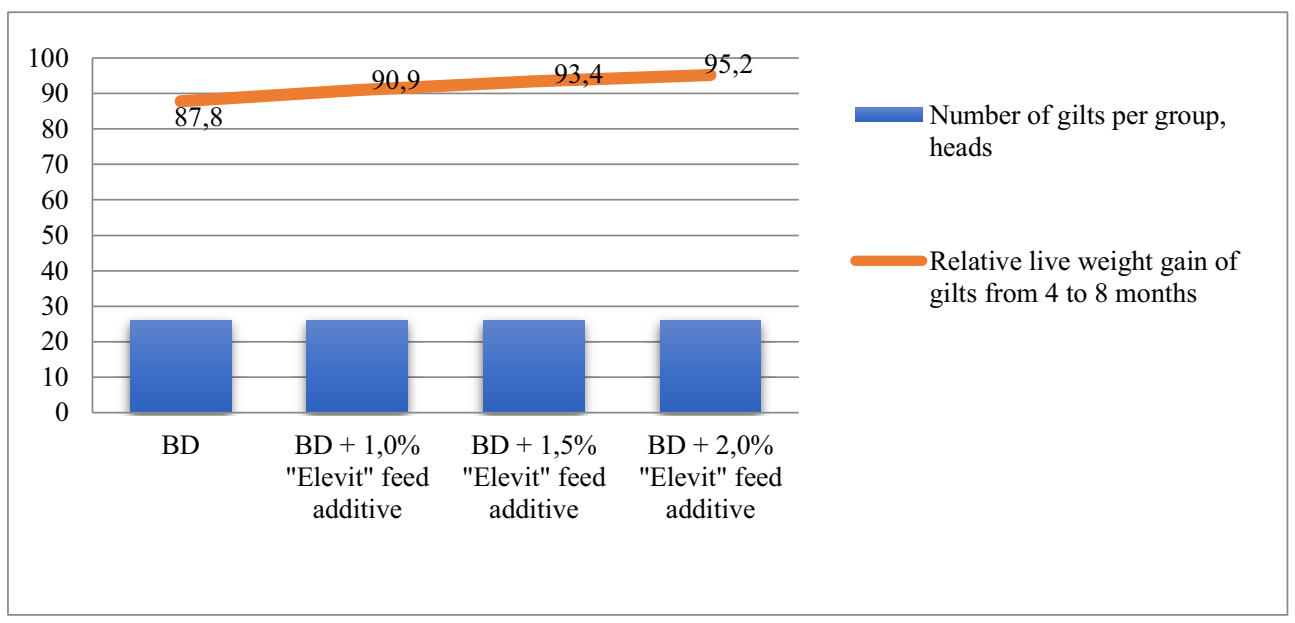

Fig. 2. Relative increase in live weight of gilts depending on feeding them with "Elevit" feed additive.

The analysis of the data shown in Figure 2 allows to draw a certain conclusion, namely: with the increase in "Elevit" feed additive dosage in experimental gilts' diets from 1.0 to $2.0 \%$, there is a relative increase in these gilts' live weight by $3.1 ; 5.6 ; 7.4 \%$ compared to the first control group that did not receive the feed additive. Such a rapid relative increase in the experimental rearing gilts' live weight also led to the acquisition of higher live weight at 8 months compared to their peers from the control group. 
It is known that it is necessary to pay attention to the animals' development when studying the growth of rearing young pigs. After all, this indicator is always a concomitant to growth. With this, we have also studied the development of internal organs in rearing gilts with different levels of "Elevit" feed additive feeding. To do this, 3 pigs from each group were slaughtered. The data from these studies are given in Figure 3.

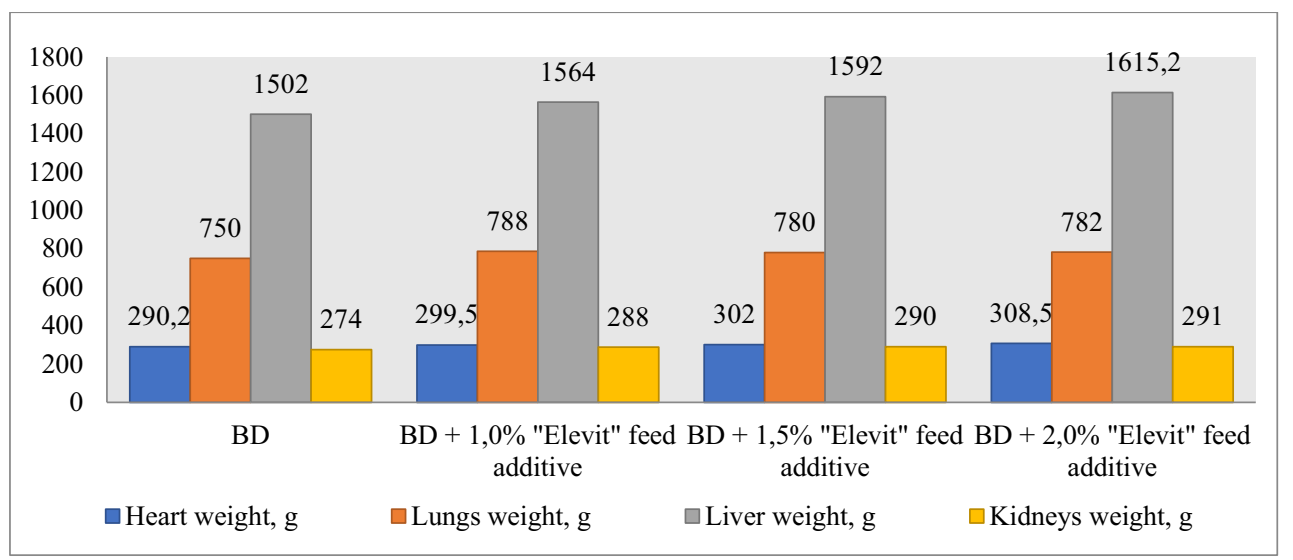

Fig. 3. Development of internal organs in rearing gilts depending on "Elevit" feed additive.

Figure 3 data analysis shows that additional introduction of "Elevit" feed additive to the rearing gilts' diet at different dosages $-1.0 ; 1.5 ; 2.0 \%$ above the basic diet positively affects the development of these animals' internal organs (heart, lungs, liver, kidneys). When reaching 8 months, gilts of experimental groups exceeded their peers from the control group in heart mass by $3.2 ; 4.1 ; 6.3 \%$; lungs - by $3.7 ; 4.0 ; 4.2 \%$; liver - by $5.1 ; 5.8$; $6.2 \%$, respectively. These data indirectly support a higher metabolism in rearing gilts of experimental groups.

In the general chain of pork production, the most important site is the pigs' reproduction room. The initial success depends on reproduction room's operation, because it is the beginning from which the pork production of all long-term versatile work of a huge workers' complex begins. Upon reaching 8 months, rearing gilts were transferred to the reproduction room, where further studies were carried out to study reproducible functions. Thus, oestrus in experimental gilts was determined by the standard method with the use of trailer boars twice a day, in the morning and in the evening. Gilts exhibiting oestrus were transferred to an artificial insemination point. In this point, sows were inseminated twice after sampling and exactly 24 hours later.

The results of the oestrus manifestation by rearing gilts depending on the amount of "Elevit" feed additive are presented in Figure 4. 


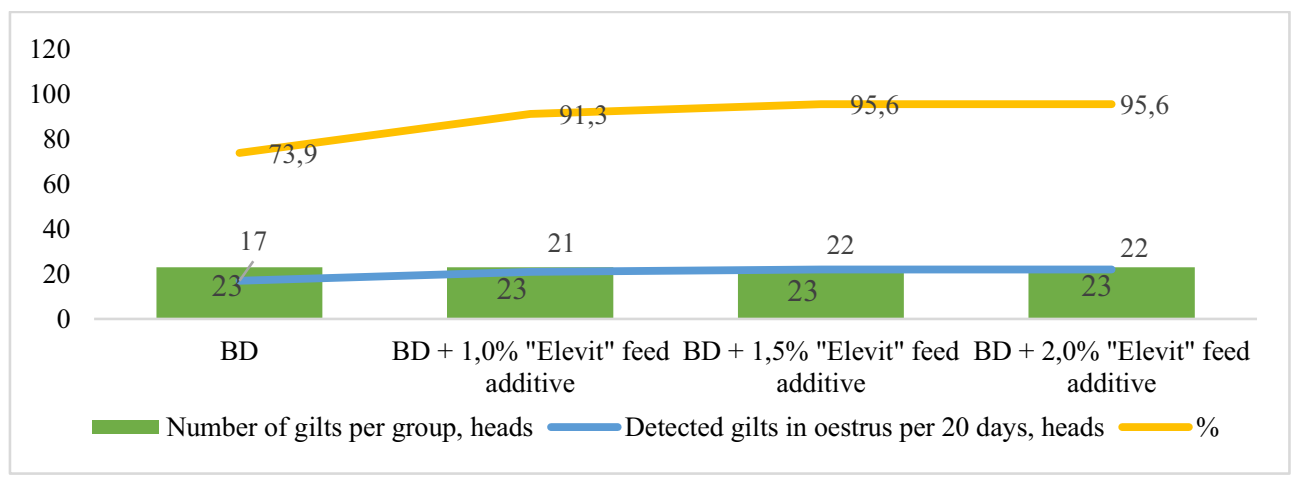

Fig. 4. Oestrus manifestation by rearing gilts depending on the feed additive "Elevit" during the growing period.

According to the data shown in Fig. 4, additional introduction of "Elevit" feed additive to the rearing gilts' basic diet at a dosage of $1.0 ; 1,5 ; 2.0 \%$ leads to an increase in their oestrus manifestation by respectively $17.4 ; 21.7 ; 21.7 \%$ compared to the control group.

In turn, the effectiveness of rearing gilts' artificial insemination at different doses of "Elevit" feed additive during breeding is shown in table 1.

Table 1. Effectiveness of rearing gilts' artificial insemination depending on "Elevit" feed additive feeding during the breeding period.

\begin{tabular}{|c|c|c|c|c|c|c|c|}
\hline \multirow{2}{*}{ 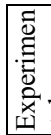 } & \multirow{2}{*}{$\begin{array}{l}\text { Conditions of feeding } \\
\text { rearing gilts during } \\
\text { breeding }\end{array}$} & \multirow{2}{*}{$\begin{array}{c}\text { Number of } \\
\text { inseminated } \\
\text { rearing gilts, } \\
\text { heads }\end{array}$} & \multicolumn{2}{|c|}{ Of them farrowed } & \multicolumn{2}{|c|}{ Obtained piglets, heads } & \multirow{2}{*}{$\begin{array}{c}\text { Average live } \\
\text { weight of } 1 \\
\text { piglet at birth, } \\
\mathrm{kg}\end{array}$} \\
\hline & & & number & $\%$ & total & $\begin{array}{c}\text { per } 1 \\
\text { farrowing }\end{array}$ & \\
\hline 1 & Basic diet & 17 & 13 & 76.4 & 121 & $9.30 \pm 0.10$ & $1.25 \pm 0.01$ \\
\hline 2 & $\begin{array}{l}\mathrm{BD}+1.0 \% \text { "Elevit" } \\
\text { feed additive }\end{array}$ & 21 & 17 & 80.9 & 165 & $9.70 \pm 0.12$ & $1.24 \pm 0.01$ \\
\hline 3 & $\begin{array}{c}\mathrm{BD}+1.5 \% \text { "Elevit" } \\
\text { feed additive }\end{array}$ & 22 & 18 & 81.8 & 178 & $9.88 \pm 0.15$ & $1.24 \pm 0.01$ \\
\hline 4 & $\begin{array}{c}\mathrm{BD}+2.0 \% \text { "Elevit" } \\
\text { feed additive }\end{array}$ & 22 & 18 & 81.8 & 180 & $10.00 \pm 0.10$ & $1.25 \pm 0.01$ \\
\hline
\end{tabular}

From the data given in Table 1 it can be seen that gilts receiving "Elevit" feed additive together with the diet at a dosage of $1.0 ; 1.5 ; 2.0 \%$ exceeded their peers from the control group in fertilization indicator by $4.5 ; 5.4 ; 5.4 \%$, and multifertility - by $4.3 ; 6.2 ; 7.5 \%$ respectively. As for the live weight of piglets at birth obtained from experimental rearing gilts, this indicator did not depend on the "Elevit" feed additive fed to gilts during breeding.

Thus, feeding "Elevit" feed additive to rearing gilts during their breeding from 4 to 8 months of age in the amount of $1.0 \%$ in addition to the basic diet resulted in full replacement of the main sows' herd, which was confirmed by the results obtained in our studies.

\section{References}

1. S.N. Aleinik, G.S. Pokhodnya, A.N. Dobud'ko, Reproductive function and productivity of purebred and mongrel boars of large white breed and Yorkshire breed, 30 (2020)

2. A.M. Khokhlov, G.S. Pokhodnya, Agrarian Science, 10, 13-16 (2006)

3. I.F. Gorlov, L.A. Breusova, Bulletin of the Russian Academy of Agricultural Sciences, 1, 31 (2013) 
4. N.I. Zhernakova, A.N. Dobudko, T.A. Malakhova et al. Optimization of rearing gilts' keeping during their breeding, 27 (2016)

5. S.N. Aleynik, Achievements of science and technology of the AIC, 6, 26-28 (2008)

6. G.S. Pokhodnya, Main breeds of pigs of meat productivity direction, 28 (2006)

7. Yu.P. Breslavets, Growth, development and meat qualities of pigs when feeding them a chlorella suspension, 37 (2015)

8. A.T. Mysik, G.S. Pokhodnya, T.A. Malakhova et al., Zootechnics, 3, 24-28 (2020)

9. G.I. Gorshkov, A.G. Narizhny, E.G. Fedorchuk, Zootechnics, 5, 8-10 (2014)

10. L.N. Gamko, D.K. Ufimtsev, Feed Production, 2, 45-46 (2011)

11. A.T. Mysik, N.N. Sorokina, N.B. Ordina et al., Zootechnics, 12, 14-17 (2019)

12. Beck John. PLOS ONE. Thom. 5(5), 1-16 (2018)

13. H. Hammami, B. Rekik, C. Bastin, et al., J. Dairy Sci., 92(9), 4604-4612 (2019)

14. J. Lewis, J. Abas, C. Dadousis, et al., PLOS ONE, 6(4), 18-27 (2015)

15. E. Serousi, Glick., A. Shirak et al., BMC Genomics, 11, 673-701 (2015)

16. J. Weller, M. Ron, Dairy Sci., 94(3), 1082-1090 (2016)

17. M. Gautier, D. Laloe, Katayoun Moazami-Goudarzi. PLOS ONE. 5(9), 13-38 (2016)

18. A.M. Khokhlov, A.S. Smirnova, V.I. Gerasimov, G.S. Pokhodnya, N.I. Zhernakova, P.P. Kornienko, Pig breeding and pork production technology: Collection of scientific works of the scientific school of Professor G.S. Pokhodnya, 10, 200-203 (2016)

19. V.P. Zhabinskaya, N.S. Trubchaninova, G.S. Pokhodnya, D.V. Korobov, V.I. Kotarev, O.E. Tatyanicheva, N.B. Ordina, International of Advanced Biotechnology and Research (VABR) ISSN 0976-2612, Online ISSN 2278-599X, 10(1), 47-53 (2019)

20. Pokhodnya, Zootechnics, 11, 22-25 (2020) 